Introduction The risk of transmission of blood-borne pathogens, including hepatitis B virus (HBV) to healthcare workers (HCWs) is well known. Under current European Union (EU) legislation, all employers have to perform a risk assessment to identify workers exposed to HBV and offer them vaccination. Immunisation should be done as early as possible after the start of their career to avoid HBV infection and the development of an infectious carrier state In 2005 we performed a survey on HBV prevention in HCWs in the EU; in 2010, a new EU Directive (2010/32/EU), on sharp injuries, to be implemented in national legislation by 11 May 2013, made an update of the 2005 survey necessary.

Methods We performed an electronic survey of national representatives from the Occupational Medicine section of the European Union of Medical Specialists (UEMS) in all countries, to find out how policies have been put into practice in the European countries.

Results Answers were received from 21 countries, representing $78 \%$ of the population in the EU-28. HBV vaccination was mandatory for medical and nursing staff in 10 countries, mandatory for other paramedical staff, medical and nursing students in nine countries, for paramedical students in eight countries, for cleaning staff in 6 countries, for technical staff in 5 countries. It was recommended in all other participating countries. Serotesting before vaccination was done in eight countries. The vaccination schedule most often used was 0,1 , 6 months (18 countries). Serotesting after vaccination was done in 18 countries, boosters were recommended in 14 countries. A non-responder policy, including testing for carrier state, was present in 18 countries.

Discussion More consultation between key actors from countries at EU level could help to optimise the way this matter is dealt with in different countries in order to contribute to further reducing $\mathrm{HBV}$ transmission to HCWs.

\section{1 (MIS)USING RANDOMISED CONTROLLED TRIALS AS A HEGEMONIC WEAPON: THE CASE OF MANDATORY INFLUENZA VACCINATION FOR HEALTHCARE WORKERS IN CANADA}

Annalee Yassi ${ }^{*}$, Karen Lockhart. School of Population and Public Health (SSPH), University of British Columbia (UBC), Vancouver, BC, Canada

\subsection{6/oemed-2018-ICOHabstracts.985}

Introduction In 2013, British Columbia, Canada, instituted a Policy requiring healthcare workers (HCWs) to accept influenza vaccination or wear a mask at work throughout the influenza season. The Policy's stated objectives (prevent influenza transmission to vulnerable patients; reduce influenza morbidity and mortality; and reduce worker absenteeism) did not refer to the health of HCWs. Moreover, the four randomised controlled trials (RCTs) cited as evidence supporting this influenza vaccine-or-mask policy were misinterpreted (or misrepresented) by its proponents, which, we argue, not only threatens the health of workers, the public and patients, but jeopardises the credibility of public health institutions.

Methods Plausibility of the four RCT findings attributing indirect patient benefits to HCW influenza vaccination were assessed by international experts comparing percentage reductions in patient risk reported by the RCTs to predicted values; we synthesise the results of the analysis and discuss the political factors that may explain the (mis)use of the RCT evidence.
Result Each RCT violated the basic mathematical principle of dilution by reporting greater percentage reductions with less influenza-specific patient outcomes and/or patient mortality reductions exceeding even favourably derived predicted values by at least $6-15$-fold. Contextual factors more likely to explain the RCT results were ignored. The prioritisation of quantitative data masks the economic and political agendas of policy makers.

Discussion This policy is a case of (mis)use of RCT evidence as a weapon against workers while transferring large amounts of public funds to a questionable program and ultimately to pharmaceutical companies. We argue that worker acceptance of influenza vaccination should be voluntary, and public resources be more appropriately allocated to measures more likely to result in greater public health benefit, such as improved sick leave to encourage ill workers to stay home, or more staffing to allow HCWs to be more vigilant with infection control procedures.

\section{OCCUPATIONAL PATHOLOGY IN DIGESTIVE ENDOSCOPY: RISKS, DISEASES AND PREVENTION}

${ }^{1}$ CP Păntea, ${ }^{2}$ LG Moise, ${ }^{3}$ IA Pântea. 'Unirea Medical Centre, Bacau, Romania; ${ }^{2}$ Colentina Hospital, Bucharest, Romania; ${ }^{3}$ Luxor Clinic,Bacau, Romania

\subsection{6/oemed-2018-ICOHabstracts.986}

Personnel working in an endoscopy digestive laboratory may be exposed to a series of harmful factors to health. Among them, the most common are patients ${ }^{6}$ biological waste, potentially infected with transmissible bacteria in the healthcare practices, chemicals used for cleaning and disinfection of the endoscopic equipment, which may determine allergies, radiation, different movements and postures, which by overload may determine musculoskeletal diseases. Selected protective equipment, used and removed properly protects the medical personnel of harmful factors at which may be exposed while working in digestive endoscopy laboratory. However, some studies made on digestive endoscopy personnel have shown a deficient conformation at standard precautions for the control of infections' transmission, and other studies have shown that very few endoscopists have modified their activity with the purpose of preventing some maladies linked to occupational health.

In this paper we propose an overview of occupational pathology in digestive endoscopy, insisting upon description of harmful factors that may be exposed the medical staff working in a digestive endoscopy laboratory and of ways of diminishing the risk of developing various diseases. Romanian medical literature dedicated to occupational pathology in digestive endoscopy is very poor, which indirectly indicates the low level of awareness of this medical problem importance, in which, inadequate information merges with ignorance and legislative gaps.

\section{WHAT ARE THE ISSUES AND THE FUTURE FOR HEALTHCARE WORKERS AND WHAT PART DOES OCCUPATIONAL HEALTH AND SAFETY PLAY?}

Janice Riegen*, Courtenay Kenny*. Waitemata District Health Board, Auckland, New Zealand

10.1136/oemed-2018-ICOHabstracts.987 